\title{
Pricing Stock Options with Stochastic Interest Rate ${ }^{\dagger}$
}

\author{
Menachem Abudy* and Yehuda Izhakian**
}

\begin{abstract}
This paper constructs a closed-form generalization of the Black-Scholes model for the case where the short-term interest rate follows a stochastic Gaussian process. Capturing this additional source of uncertainty appears to have a considerable effect on option prices. We show that the value of the stock option increases with the volatility of the interest rate and with time to maturity. Our empirical tests support the theoretical model and demonstrate a significant pricing improvement relative to the Black-Scholes model. The magnitude of the improvement is a positive function of the option's time to maturity, the largest improvement being obtained for around-the-money options.
\end{abstract}

\section{JEL Classification: G12, G13}

Keywords: Option, call option, put option, stochastic interest rate, term structure of interest rates, Black and Scholes, put-call parity.

* Graduate School of Business Administration, Bar Ilan University, menachem.abudy@biu.ac.il. Work phone number: +972-3-5318907.

** Department of Economics, Stern School of Business, New York University, yud@stern.nyu.edu. Work phone number: +1212-998-0017

$\dagger$ We benefited from discussions with Simon Benninga, Abraham Lioui, Isaac Meilijson, Saggi Katz, Zeev Schuss, Ramon Rabinovitch and Fernando Zapatero. Yehuda Izhakian thanks the Lady Davis Foundation, Hebrew University of Jerusalem, for their support. 


\section{Introduction}

In their breakthrough paper Black and Scholes (BS, 1973) derived a closed-form solution for pricing European options assuming that the price of the underlying asset follows a geometric Brownian motion with constant drift and constant volatility, while the interest rate remains constant during the entire option life. We relax the assumption that the price of the underlying asset is the only source of uncertainty by allowing the interest rate to be stochastic, and examine theoretically and empirically how this additional source of uncertainty affects call and put option prices. Pricing accuracy is highly important, since options are widely used as in investment strategies, and any small pricing error can results in significant losses.

This paper contributes to the existing literature by introducing a new closed-form option pricing formula that demonstrates a significant decreasing in pricing errors of European stock options. First, the theoretical framework provides a useful methodology for valuing put and call stock options, which maintain non-arbitrage properties such as the put-call parity. Second, we document a significant pricing improvement using the stochastic interest (SI) model relative to the Black-Scholes (BS) model. Since the latter serves as a common standard in pricing contingent claims, using the SI model has practical implications when market prices are missing, especially for long-term options (in which we demonstrate the highest significant improvement: up to $47 \%$ for call options and $43.5 \%$ in put options).

This paper derives a new closed-form solution for European options with Gaussian short-term interest rate (henceforth the SI model). ${ }^{1}$ We suggest a construction

\footnotetext{
${ }^{1}$ Our option pricing formula does not appear in Haug's (2007) book.
} 
method and proof that are different from those described in the literature, and apply them in an extension of the BS model that incorporates the Merton (1973) and the Vasicek (1977) term structure of interest rates models. ${ }^{2,3}$ Our method does not rely on a replicated continuously rebalanced portfolio and yields an applicable and friendly mathematical expression for option pricing. ${ }^{4}$

Our SI model is motivated by the insight that option prices reflect only the unexpected part of path-dependent excess returns. Call options price only the positive abnormal excess returns, while put options price only negative abnormal excess returns. This perception guides us in proving a closed-form solution for pricing options under stochastic interest rates. We show that incorporating the uncertainty of short-term interest rates raises the value of stock options. The longer the time to maturity and the higher the interest rate volatility, the higher the value. In fact, when the interest rate is stochastic, we have an additional implicit option: an option on the interest rate. ${ }^{5}$

We conduct empirical tests to compare the performance of the SI model to the performance of the BS model using 24,766 call options contracts and 36,837 put contracts on the S\&P 500 index for the period between January 3, 2005 and December 30, 2006. Performance is measured relative to the actual option prices in the market; the

\footnotetext{
${ }^{2}$ Although Gaussian term structure models can possibly assign a positive probability for negative interest rates in the long-run, the simplicity of these models and the fact that most options do not have a time to expiration long enough to get to this point, makes them a good choice for our purpose.

${ }^{3}$ The literature modelling the stochastic nature of the term structure of interest rates is vast. Examples of single-factor models include Brennan and Schwartz (1977), Dothan (1978), Cox, Ingersoll and Ross (1985), Ho and Lee (1986), Black and Karasinski (1991) and Heath, Jarrow and Morton (1992).

${ }^{4}$ Our method can also be applied to non-Gaussian term structure models.

${ }^{5}$ See Ho, Stapleton and Subrahmanyam (1997).
} 
closer the prices evaluated by the model are to the actual market prices, the more accurate is its performance considered to be. Our results show that the SI model provides a better estimation than the BS model using the mean square error (MSE) criterion. For example, the comparison over the total sample shows that the SI model yields an average accuracy improvement in MSE of $29.51 \%$ for call options and $19.69 \%$ for put options relative to BS model. ${ }^{6}$

We find fewer pricing errors (relative to the market price) for the SI model than for the BS model as the time to maturity of the option increases, for both call and put options. For options with less than 180 days to expiration we find that the highest mispricing magnitude is for options around the money. For options with 180 days or more to expiration, the improvement in mispricing (of the SI model relative to BS model) of put options increases as the option is more in the money; the improvement in mispricing of call options increases as the option is more out of the money. We test the statistical significance of the mispricing differences between the models using the Huang and $\mathrm{Wu}(2004)$ measure, and find that most of the mispricing differences are significant across moneyness and time to maturity of the options. Our results are robust to out-ofsample estimation of the interest rate term structure parameters.

The empirical evidence of option pricing models with stochastic interest rate is mixed. On the one hand, Rindell (1995) tests the Amin and Jarrow (1992) model using (only) index call options from the Swedish option market and shows that the Amin and Jarrow (1992) model outperforms the BS model. On the other hand, Kim (2002) uses

\footnotetext{
${ }^{6}$ The MSE improvement represents reduction in percentage of the MSE estimation of the SI model relative to the BS model.
} 
data of index call options on the Nikkei 225 index and compares between stock option models with stochastic interest rate. He finds that incorporating stochastic interest rates into option pricing does not improve the performance of the BS pricing formula. Our findings are aligned with those of Rindell (1995), who finds an improvement in performance relative to the BS model. We contribute to this literature by providing an empirical examination on both call and put options using our model on U.S. data. In addition, contrary to Rindell (1995) and Kim (2002), we use the common approach for examining the performance of option pricing models, combined with a more recent methodologies of statistical significant such as the Huang and Wu (2004) measure.

Our model integrates into the family of option pricing models that incorporate the stochastic nature of the short-term interest rate. Generally speaking, in this family models differ in the stochastic process (usually single factor) that governs the short-term interest rate and in the sources of uncertainty. For example, Bailey and Stulz (1989), Goldstein and Zaopatero (1996) and Kaushik and Ng (1993) assume a single source of uncertainly for both the underlying asset and the interest rate. Bailey and Stulz (1989) assume a single-product economy with a representative investor with a constant relative risk tolerance; Goldstein and Zapatero (1996) consider a general equilibrium in a continuous version of the Lucas (1978) exchange economy and Kaushik and Ng (1993) assume stochastic consumption growth and introduce a preference-dependent option model. Bakshi, Cao and Chen (1997) and Bakshi and Chen (1997a) present option pricing models with stochastic volatility, which are different in nature. However, both models assume that changes in the interest rate and the return of the underlying asset are uncorrelated. Despite its richness, the Bakshi-Chen (1997a) model is not easy to 
implement in practice, since identifying the economy-wide factors and the firm-specific factors is not simple. ${ }^{7,8}$ Brenner et al. (1987) assume that the short-term interest rate follows a mean reverting stochastic process, in presenting a numerical analysis inquiring into the impact of interest rate uncertainty on the price of stock index options.

The work most closely related to the theoretical part of this paper is Rabinovitch (1989). However, our model differs in several respects from Rabinovitch (1989): First, we construct a simpler closed-form solution with fewer parameters than Rabinovitch (1989). ${ }^{9}$ Second, while Rabinovitch's model prices European call options, we also derive a closed-form solution for the price of a European put option, and demonstrate that our pricing method maintains the non-arbitrage argument of the put-call parity. In addition, when resetting the interest rate term structure parameters the Rabinovitch model does not converge to the BS model, while our does. Finally, the empirical tests show that our pricing improvements to the BS model are significantly better than those of Rabinovitch.

Our theoretical model differs from the above models in that it has two sources of uncertainly, namely the interest rate and the underlying asset. Moreover, we do not impose any assumption on the correlation between the interest rate and the return on the underlying asset, and we employ parameters which can be empirically estimated and used to evaluate options in practice.

\footnotetext{
${ }^{7}$ See also Bakshi and Chen (1997b), who suggest a model for the valuation of foreign exchange claims in equilibrium.

${ }^{8}$ Additional examples of models of this type have been presented by Ho, Stapleto and Subrahmanyam (1997) and Scott (1997). Further, the Merton (1973) model provides the basis for subsequent papers by Amin and Jarrow (1992) and Miltersen and Schwartz (1998).

${ }^{9}$ See also Chen (1991). In addition to the parameters that characterize the term structure of interest rates, Rabinovitch's (1989) model also uses a bond's price (with the same maturity of the stock option), its instantaneous expected return and its instantaneous return variance.
} 
A possible application of the SI model is in the valuation of employee stock options (ESOs), which are usually granted for a period of 10 years. According to accounting standard ASC 718, firms that grant stock options to employees must report them as an expense in their financial reports. Using the SI model for such cases would lower the estimation errors caused by the BS assumptions.

The rest of this paper is organized as follows. Section 2 establishes the fundamental framework of the SI model and suggests a model for call and put option pricing that incorporates a stochastic term structure of interest rates. Section 3 simulates the effect of specific model parameters on the pricing model. Section 4 investigates the effect of stochastic interest rates on pricing call and put options, and presents an empirical comparison of the SI model with the BS model. Section 5 concludes.

\section{The model}

In this section we introduce our main theorems. We first establish the fundamentals of the model and then present the SI pricing model for European call and put stock options. In general, we relax the assumption of constant short-term interest rates and propose a generalization of the $\mathrm{BS}$ model to incorporate a stochastic term structure of interest rates. ${ }^{10}$

\section{A. Preliminaries}

Assume a non-dividend paying underlying asset. Let $S(t)$ be its price at the initial time $t$, and let its price at time $T$ be $S(T)$. The price of the underlying asset is

\footnotetext{
${ }^{10}$ The main proofs are detailed in the Appendix.
} 
characterized by a mean, $\mu$, and a standard deviation, $\sigma$, and follows the geometric Brownian motion dynamic:

$$
d S(t)=S(t)\left(\mu+\frac{1}{2} \sigma^{2}\right) d t+S(t) \sigma d Z(t)
$$

where $d Z$ is a standard Wiener process.

The short-term interest rate $r$ is assumed to follow a single-factor Gaussian process,

$$
d r(t)=(\alpha-\beta r(t)) d t+\xi d H(t)
$$

where $d H$ is a standard Wiener process under an equivalent martingale probability measure, $\xi$ is the standard deviation of the short-term interest rate, and $\alpha$ and $\beta$ are constant coefficients. We assume that $Z$ and $H$ are correlated with coefficient $\rho$, i.e. $d Z d H=\rho d t .^{11}$

If all the three coefficients, $\alpha, \beta$ and $\xi$, that characterize the term structure model, are equal to zero then the short-term interest rate and the discount factor are constant. If, however, at least one of the coefficients is not zero then we get a stochastic short-term interest rate and, thus, a stochastic discount factor. Explicitly, if $\alpha \neq 0, \xi \neq 0$ and $\beta=0$ then the Merton (1973) and the Ho and Lee (1986) term structure models of interest rate are obtained. If, however, $\alpha \neq 0, \beta \neq 0$ and $\xi \neq 0$, then the Vasicek (1977) model of short-term interest rate is obtained. ${ }^{12}$

The path-dependent discount factor is defined by

\footnotetext{
${ }^{11}$ For simplicity we prove our results for the case of time-independent coefficients; $\alpha, \beta$ and $\xi$. The model can, however, be extended to the case of time-dependent coefficients.

${ }^{12}$ In these cases the short-term interest rate follows a mean-reverting Ornstein-Uhlenbeck process.
} 


$$
\Upsilon(t, T)=\frac{1}{R(t, T)}
$$

where

$$
R(t, T)=\exp \left(\int_{t}^{T} r(u) d u\right), \quad \forall t \in[0, T] .{ }^{13}
$$

The excess-return factor, $X(t, T)$ conditional on a random sample path during a holding period $\tau=T-t$, is

$$
X(t, T)=\frac{S(T)}{S(t) R(t, T)}
$$

with the boundary condition $X(t, t)=1$. Literally, the excess-return factor is the portion of the underlying-asset price which is purely attributed to risk. The natural logarithm of this factor is the path-dependent excess return of a risky asset. We define the normalization factor as the expectation of the excess-return factor:

$$
F(t, T)=\mathrm{E}[X(t, T)]
$$

The natural logarithm of the normalization factor, $\ln [F(t, T)]$, is the risk premium for holding a risky asset during the period $\tau=T-t$.

\section{B. European call stock options under stochastic interest rate}

A call stock option with exercise price $K$, written at time $t$ on a non-dividendpaying underlying asset with price $S(t)$ and volatility $\sigma$, pays

\footnotetext{
${ }^{13}$ The accumulation factor, $R(t, T)$, is one plus the short-term interest rate, conditional on a continuous sample path, and can be interpreted as the outcome of $\$ 1$ continually reinvested in the risk-free asset.
} 
$(S(T)-K)^{+}=\max (S(T)-K, 0)$ at maturity time $T$. The following theorem states our main theoretical result.

Theorem 1: At time $t$ the price of a European call option with exercise price $K$ at maturity time $T$ is

$$
\begin{aligned}
C(t, T) & =S(t) \mathrm{N}\left(\frac{\ln \frac{S(t)}{K}+A(t, T)-\frac{1}{2} v^{2} \tau}{\sigma \sqrt{\tau}}+v \sqrt{\tau}\right)^{-A(t, T)+\frac{1}{2} B^{2}(t, T) \tau} \mathrm{N}\left(\frac{\ln \frac{S(t)}{K}+A(t, T)-\frac{1}{2} v^{2} \tau}{\sigma \sqrt{\tau}}-B(t, T) \sqrt{\tau}\right)^{\prime}, \\
& -K e^{-},
\end{aligned}
$$

where $\mathrm{N}(\cdot)$ denotes the standard normal cumulative probability distribution, $\tau=T-t$ stands for the time to maturity, $v^{2}=\sigma^{2}+B^{2}(t, T)-2 \rho \sigma B(t, T)$, and the functions $A(t, T)$ and $B(t, T)$ are defined as follows:

i. If $\beta=0 \quad$ then $\quad A(t, T)=r(t) \tau+\frac{1}{2} \alpha \tau^{2} \quad$ and $\quad B(t, T)=\frac{1}{\sqrt{3}} \xi \tau^{\frac{3}{2}}$

ii. If $\beta \neq 0$ then $A(t, T)=\frac{\alpha}{\beta} \tau+\left(r(t)-\frac{\alpha}{\beta}\right) \lambda(t, T)$ and

$$
B(t, T)=\frac{\xi}{\beta} \sqrt{\tau-\lambda(t, T)-\frac{\beta}{2} \lambda^{2}(t, T)}, \text { where } \lambda(t, T)=\frac{1}{\beta}\left(1-e^{-\beta \tau}\right)
$$


Theorem 1 generalizes the BS call option pricing model to the case of stochastic interest rates. ${ }^{14}$ In the $\mathrm{BS}$ model the price, $C(t, T)$, of the option is a function of the time to maturity, $\tau=T-t$, the price of the underlying asset, $S(t)$, at time $t$, its volatility, $\sigma$, and a constant risk-free rate. In our model the price of the option is also a function of the parameters characterizing the interest rate, $\alpha, \beta$ and $\xi$, and the correlation between the interest rate and the underlying asset, $\rho .{ }^{15}$

Theorem 1 extends the BS model by capturing an additional source of uncertainty introduced by the randomness of the interest rate. Intuitively, including the effect of random interest rates has a similar effect to increasing the variance of the underlying asset, which results in a positive effect on the option price. As we demonstrate below, the call price is increasing with the time to maturity and with the variance of the shortterm interest rate, and decreasing with the correlation between the price of the underlying asset and the short-term interest rate. If the underlying asset is a bond, the correlation coefficient between the dynamics of the underlying asset and the dynamics of the interest rate is $\rho=1$, so that there is only one source of uncertainty. ${ }^{16}$

Corollary 1, below, shows that if the interest rate $r$ is constant over time, then the SI model collapses to the BS model.

\footnotetext{
${ }^{14}$ As in the classical BS model, when the stock pays no dividends, the price of a European call option equals the price of an American call option.

${ }^{15}$ A detailed empirical analysis of the effect of these parameters on the option price is presented in the following section.

${ }^{16}$ See also Chen (1991).
} 
Corollary 1: If the interest rate is constant over time then the call option pricing model in Theorem 1 collapses to the BS model.

Proof: If the interest rate, $r$, is constant then $\alpha=0, \beta=0$ and $\xi=0$, and Equation (2) becomes $d r(t)=0$. Therefore $A(t, T)=r(t)(T-t)=r \tau$ and $B(t, T)=0$. Substituting into Equation (4) of Theorem 1 gives the standard BS formula.

\section{Intuition}

The intuition of Theorem 1 is that the price of a call (put) option is determined by the states of nature in which the unexpected excess return is higher (lower) than a given implicit threshold.

A sample path of asset returns is composed of three components: compensation for time, expected excess return and unexpected excess return (the last two components compensate for risk). The price of the underlying asset is determined by the expected return, which consists of compensation for time and for risk (expected excess return). Option prices are derived solely from the unexpected excess return of the underlying asset. The price of a call option considers positive unexpected excess returns while the price of a put option considers negative unexpected excess returns. Therefore, the price of a European call option can be evaluated by

$$
C(t, T)=\mathrm{E}\left[\Upsilon(t, T)\left(\frac{S(T)}{F(t, T)}-K\right)^{+}\right],
$$

and the price of a European put option by

$$
P(t, T)=\mathrm{E}\left[\Upsilon(t, T)\left(K-\frac{S(T)}{F(t, T)}\right)^{+}\right] .
$$


The normalization factor, $F(t, T)$, represents the portion of expected excess returns. Thus, the expression $\frac{S(T)}{F(t, T)}$ represents the unexpected portion of the price, i.e. the future adjusted price of the underlying asset after eliminating the effect of expected returns. Equation (5) suggests that the price of a call option is the sum of the discounted abnormal asset's prices over all states of nature in which the adjusted price is higher than the exercise price. Writing the call option price as

$$
C(t, T)=S(t) \mathrm{E}\left[\left(\Upsilon(t, T) \frac{S(T)}{S(t) F(t, T)}-\Upsilon(t, T) \frac{K}{S(t)}\right)^{+}\right]
$$

the expression $\frac{\Upsilon(t, T) S(T)}{S(t) F(t, T)}$ is, then, one plus the unexpected excess return. Pricing the call option takes into account only the states of nature in which the unexpected excess return $\ln \left[\frac{\Upsilon(t, T) S(T)}{S(t) F(t, T)}\right]$ exceeds the threshold $\ln \left[\Upsilon(t, T) \frac{K}{S(t)}\right]$.

In the BS model the unexpected excess return is caused by a single source of randomness: the price of the underlying asset. In our model the unexpected excess return has an additional source of randomness: the discount factor, which is governed by the stochastic behavior of the short-term interest rate. This is the reason that in most cases the BS underprices in comparison to the SI model.

\section{European put stock options and the put-call parity}

In this section we propose a formula for pricing put stock options and use it to prove the existence of the put-call parity under our framework. Theorem 2 below uses a 
technique identical to that of Theorem 1 to introduce a pricing model for European put stock options. ${ }^{17}$

Theorem 2: At time $t$ the price of a European put option with maturity time $T$ and exercise price $K$ is

$$
\begin{aligned}
P(t, T) & =K e^{-A(t, T)+\frac{1}{2} B^{2}(t, T) \tau} \mathrm{N}\left(-\frac{\ln \frac{S(t)}{K}+A(t, T)-\frac{1}{2} v^{2} \tau}{\sigma \sqrt{\tau}}+B(t, T) \sqrt{\tau}\right) \\
& -S(t) \mathrm{N}\left(-\frac{\ln \frac{S(t)}{K}+A(t, T)-\frac{1}{2} v^{2} \tau}{\sigma \sqrt{\tau}}-v \sqrt{\tau}\right),
\end{aligned}
$$

where $\mathrm{N}(\cdot)$ denotes the standard normal cumulative probability distribution, $\quad \tau=T-t$ stands for the time to maturity, $\quad v^{2}=\sigma^{2}+B^{2}(t, T)-2 \rho \sigma B(t, T)$, and the functions $A(t, T)$ and $B(t, T)$ are defined as follows:

i. If $\beta=0$ then $A(t, T)=r(t) \tau+\frac{1}{2} \alpha \tau^{2} \quad$ and $\quad B(t, T)=\frac{1}{\sqrt{3}} \xi \tau^{\frac{3}{2}}$;

ii. If $\beta \neq 0$ then $A(t, T)=\frac{\alpha}{\beta} \tau+\left(r(t)-\frac{\alpha}{\beta}\right) \lambda(t, T)$ and

$$
B(t, T)=\frac{\xi}{\beta} \sqrt{\tau-\lambda(t, T)-\frac{\beta}{2} \lambda^{2}(t, T)} \text {, where } \lambda(t, T)=\frac{1}{\beta}\left(1-e^{-\beta \tau}\right) \text {. }
$$

Like Theorem 1, Theorem 2 generalizes the BS put options pricing model to the case of stochastic interest rates. As in call options, the stochastic interest rate has an

\footnotetext{
${ }^{17}$ The proof is analogous to the proof of Theorem 1.
} 
effect similar to the effect of increasing the variance of the underlying asset, which in most cases has a positive effect on the option price. This positive effect on the option price is increasing with the time to maturity and the variance of the short-term interest rate, and decreasing with the correlation between the price of the underlying asset and the short-term interest rate.

Corollary 2 demonstrates that in the case of constant interest rates our put option pricing model also collapses to the BS model.

Corollary 2: If the interest rate is constant over time then the European put option pricing formula in Theorem 2 collapses to the BS model.

Having a closed-form solution for the price of call options and put options, we prove that the put-call parity is preserved under stochastic Gaussian interest rates.

Theorem 3: The put-call parity

$$
C(t)+K \Upsilon(t, T)=P(t)+S(t)
$$

is satisfied under stochastic interest rates that follow a Gaussian process.

Apart from the fact that with stochastic interest rates there is no opportunity for arbitrage, Theorem 3 leads to the conclusion that the stochastic interest rate affects the price of both put and call options in the same (positive) direction, thus preserving the putcall-parity. 


\section{Simulation}

This section presents a number of simulations, all based on common parameters, that shed light on the effect of stochastic interest rates on the prices of put and call stock options. Our simulations examine the value of at-the-money call and put options.

Figure 1 presents the values of the BS model, the SI model using the Merton (1973) term structure and the SI model using the Vasicek (1977) term structure as a function of time to maturity. In call options, an increase in time to maturity increases the value of the option in all the models. Nevertheless, the highest value appears in the SIVasicek model, followed by the SI-Merton model. The intuition is that since the time value in a call option is positive and the SI models also price the interest-rate risk, an increase in time to maturity leads to higher call prices. The time value of at-the-money put options is also positive. Hence, the BS value increases as a function of time to maturity, as does the SI-Vasicek model. The SI-Merton model shows a steeper increase than the SI-Vasicek model, possibly because the Merton model is not mean reverting.

\section{[[ INSERT FIGURE 1 ]]}

Figure 2 presents the value of the BS model, the SI-Merton and the SI-Vasicek as a function of the correlation between changes in the underlying-asset return and changes in the interest rate. In call options, the correlation coefficient has a negative effect on options values, i.e. a decrease in the correlation leads to an increase in option values. The reason is that a lower correlation leads to a "noisier environment," which leads to higher option prices in the SI models. Put options present the same effect relative to the correlation coefficient, with a steeper decrease in values using the SI-Vasicek model. 


\section{[[ INSERT FIGURE 2 ]]}

Figure 3 presents the value of the BS model, the SI-Merton and the SI-Vasicek as a function of the interest rate's standard deviation, $\xi$. An increase in the standard deviation $\xi$ resembles an increase in the underlying asset's volatility, and thus has a positive effect on the SI model's option prices relative to the BS model. The BS model serves as a benchmark and obviously is not affected by changes in the interest rate term structure parameters. Notice that the effect in the SI-Vasicek model is stronger than the effect in the SI-Merton model, indicating that a negative $\beta$ has a positive effect on option prices.

\section{[[ INSERT FIGURE 3 ]]}

\section{Empirical analysis}

Using our theoretical model, we now estimate option prices using historical data. The main goal of this section is to investigate the effect of stochastic interest rates on option prices, and to examine whether the SI model is more accurate in estimating option prices than the BS model. We measure the accuracy of the models relative to the actual option prices in the market, i.e. the closer the prices estimated by the model to the actual market prices, the more accurate the model is considered to be. Our analysis is conducted in two steps. First, we estimate the parameters of the interest rate's term structure and the correlation coefficient between the underlying asset and the short-term interest rate. Then, we use these parameters in the SI and BS models, and compare their 
accuracy. ${ }^{18}$

\section{A. The short-term interest rate}

We begin with estimating the coefficients $\alpha, \beta$ and $\xi$, which characterize the stochastic nature of the short-term interest rate. We follow the methodology of Chan, Karolyi, Longstaff and Sanders (1992) and Nowman (1997), and subject to $\mathrm{E}\left(\varepsilon_{t+1}\right)=0$ and $\mathrm{E}\left(\varepsilon_{t+1}^{2}\right)=\xi^{2}$ use the discrete-time process

$$
r_{t+1}-r_{t}=\alpha_{t}+\varepsilon_{t+1}
$$

to estimate the parameters that characterize the continuous-time process in the Merton (1973) term structure model, and the discrete-time process

$$
r_{t+1}-r_{t}=\alpha+\beta r_{t}+\varepsilon_{t+1}
$$

to estimate the parameters that characterize the continuous-time process in the Vasicek (1977) term structure model. ${ }^{19}$

We estimate the term structure parameters using the yield to maturity (YTM) of the one-month Treasury-bill (T-bill) reported by CRSP's monthly treasury section. The data are monthly and cover the period from January 1960 to December 2009, providing 600 observations in total. ${ }^{20}$ For each month we select the YTM of the T-bill closest to 30

\footnotetext{
${ }^{18}$ We also compare our call option model to the Rabinovitch (1989) model. Our results indicate also a substantial improvement relative to Rabinovitch's model using the MSE measure.

${ }^{19}$ Chan et al. (1992) follow Brennan and Schwartz (1982), Dietrich-Campbell and Schwartz (1986), Sanders and Unal (1988), and others, and use a discrete-time econometric specification as an approximation for a continuous-time process.

${ }^{20}$ Chan et al. (1992) use the one-month T-bill constructed by Fama (1984). The term structure parameters are quantitatively similar if we use the one-month T-bill constructed by Fama (1984).
} 
days to maturity in absolute values. We use an OLS regression, since the discrete-time econometric specification of the continuous-time models we examine is a simple AR(1) with constant volatility. ${ }^{21}$

Table 1 summarizes the parameter estimations of Merton (1973) and Vasicek (1977) term structure models. It shows that the parameter of the Merton model is $\alpha=-0.000062$ with $\mathrm{t}$-value -0.204 and the variance is $\xi=0.00005$. The parameters of the Vasicek model are $\alpha=0.001695$ and $\beta=-0.034883$ with t-values 2.672 and -3.143 , respectively, and the variance is $\xi=0.000055$. Since the parameters of the Merton model are statistically insignificant, henceforth we concentrate on the Vasicek model in our empirical estimation.

\section{[[INSERT TABLE 1 ]]}

\section{B. The option pricing models - a comparison}

In this section we estimate the call and put option prices using the SI model and the BS model. We compare these models by examining their mispricing measures relative to the actual option price in the market, aiming to examine whether the SI model provides a better estimation than the BS model.

We choose to compare the SI model only to BS model since we find that the MSE estimations of Rabinovitch (1989) model are significantly higher than the MSE of the SI and the BS models. For example, for the total call options sample, the MSE of the SI and

\footnotetext{
${ }^{21}$ Since we are estimating a single AR(1) equation, the parameter estimators are the same if we use maximum likelihood estimation or GMM with one instrument variable.
} 
the BS models are 40.79 and 57.87, respectively, while the MSE of Rabinovitch model is 287.88.

Our empirical estimation of options is based on the S\&P 500 index call options (SPX). Options written on this index are the most actively traded European-style options (Bakshi, Cao and Chen, 1997) and have been the focus of many studies. ${ }^{22}$ In general, the market for the S\&P 500 index options is the second most active index of options in the USA and is the largest in terms of open interest (Heston and Nandi, 1997).

The data sample we use is from the period between January 3, 2005 and December 29, 2006. ${ }^{23}$ All the relevant option data are obtained from the OptionMetrics database. We calculate the mid-point of the end-of-the-day bid-ask quotes of call and put options on the S\&P 500 as a proxy for the option's end-of-the-day market price. ${ }^{24}$ The appropriate risk-free interest rate per trading day is set by matching the maturity of the option to the interest rate with the closest duration to the remaining time to expiration of the option, which appears in the zero coupon yield curve (continuously compounded) calculated by OptionMetrics. The proxy for the S\&P 500 expected volatility is the realized historical volatility of the S\&P 500. ${ }^{25,}{ }^{26}$ We follow the common practice of calculating the realized volatility over a date range of 182 calendar days..$^{27,28}$

\footnotetext{
${ }^{22}$ See, for example, Rubinstein (1995), who emphasizes that the S\&P 500 is one of the best markets for testing European pricing models, Heston (1997) and others.

${ }^{23}$ We choose a stable period of the economy. Clearly, our results will be significantly stronger in non stable periods.

${ }^{24}$ OptionMetrics provides data on the highest closing bid price and the lowest closing ask price on the S\&P 500.

${ }^{25}$ We use historical volatility rather than a measure of implied volatility (such as the VIX) since measures of implied volatility are based on specific pricing models, while we are interested in testing pricing models, not using them to derive volatility measures.
} 
For European options, the spot price needs to be adjusted to dividends. We use the annualized S\&P 500 dividend yield and adjust the index price by discounting the spot price using the adjusted dividend yield to the remaining life of the option. This contemporaneous adjusted index level is later used as an underlying-asset value in the option models. ${ }^{29}$

Examining the SI model also requires the estimation of the correlation between changes in the stochastic movement of the interest rate and the stochastic movement of the underlying asset. As a proxy for this correlation, we estimate the correlation between the S\&P 500 daily returns and the one-year T-bill daily returns from the period between January 3, 1990 and December 31, 2008. The correlation estimation obtained is insignificant, with a value of 0.001 and a $t$-statistic of $0.24 .{ }^{30}$

Following the literature, we use the conventional exclusion filters for the raw data. We exclude options whose mid-bid-ask quotes are below $\$ 0.5$ to avoid

\footnotetext{
${ }^{26}$ OptionMetrics calculates the realized volatility using a simple standard deviation calculation on the logarithm of the close-to-close daily total return.

${ }^{27}$ The common practice is to use closing prices from daily data over the most recent 90 to 180 days. See Hull (2009).

${ }^{28}$ Our results remain similar when we use data ranges between 60 day and 365 days to measure the historical volatility.

${ }^{29}$ The adjusted spot price is calculated as $\operatorname{spot} \cdot e^{-\operatorname{div} \cdot \frac{\text { time }}{350}}$, where div denotes the annual dividend yield of the S\&P 500 and time denotes the number of days remaining until the option expires.

${ }^{30}$ Most of the correlation estimations in the literature focus on a rolling estimation window and use long-term bonds (usually 10-year government bonds). See, for example, Connolly, Strivers and Sun (2007). Svensson and Dietzsch (2009) find that the estimated monthly mean correlation between the S\&P 500 returns and one-year T-bill is -0.09 (for the period from January 1982 to September 2008). Our quantitative results remain similar if we use the Svensson and Dietzsch (2009) estimation period.
} 
microstructure biases. ${ }^{31}$ In addition, to limit the effects of option expiration, we exclude options which are less than 10 days to expiration. ${ }^{32}$ We also exclude contracts that have a trading volume of less than 50 options on a given trading day to minimize the effects of bid-ask spread. ${ }^{33}$ The final sample after applying all these filters consists of 24,766 call option contracts and 36,837 put contracts.

Table 2 provides summary statistics of the option data sample. It presents the distribution of the number of call (Panel A) and put (Panel B) option contracts by moneyness (i.e. the stock price to exercise price ratio), and time to maturity. Table 2 shows that most of the call contracts $(90.6 \%)$ have moneyness between 0.94 and 1.03 , while $52 \%$ are call contracts with 60 days or less to expiration. This indicates that our empirical estimation also covers short-term options around the money. One can see that call contracts with more than 180 days to expiration are fairly active. Most of the put contracts are either short term with 60 days or less to expiration (50\%), or long term with 180 days or more to expiration (23.6\%), while $34.6 \%$ of the put contracts are deep out of the-money. In general, $73.5 \%$ of the put sample is in or out of the money.

\section{[[INSERT TABLE 2$]]$}

\section{Comparison of models}

In this section we examine the accuracy of the SI model compared to the BS model. The benchmark for our tests is the actual option price in the market. Explicitly,

\footnotetext{
${ }^{31}$ See Bakshi, Cao, and Chen (1997), Chu and Freund (1996), and Liu and Shen (2008).

${ }^{32}$ Bakshi, Cao, and Chen (1997), Hsieh and Ritchken (2005), Fleming (1998) and others use this filter.

${ }^{33}$ An additional conventional filter excludes options in which $1.2 \geq S / K \geq 0.8$. Our results are quantitatively similar when we apply this filter.
} 
we inquire into which of the price estimations of the two models deviates less from the actual price. The deviation from the actual option price is measured using the mean square error (MSE) criterion. A smaller MSE means a better estimation and a lower model mispricing. Mispricing is defined as the difference between the market price and the model value. The MSE criterion that we use is the following:

$$
M S E=\frac{1}{n} \sum_{j=1}^{n}\left(C_{j}^{\text {market price }}-C_{j}^{\text {model price }}\right)^{2}
$$

where $C_{j}^{\text {market price }}$ is observation $j$ 's market price,$C_{j}^{\text {model price }}$ is observation $j$ 's value of the option according to the model, and $n$ is the number of observations. ${ }^{34}$

Table 3 reports the MSE estimations of the SI model (Panel A) and the BS model (Panel B) relative to the market option prices, across moneyness and time to maturity, for both call and put options. It shows that the average MSE over the entire call option sample using the SI model is 48.17 , while the average MSE using the BS model is 57.87. For put options, the SI model yields an MSE of 71.48 relative to 89.01 of the BS model. For call options, both pricing models have a higher MSE the more the options are in the money and the longer the time to expiration. The MSE of put options also increases the longer the time to expiration. However, put options present a different moneyness pattern. For the same time to expiration, the MSE is smaller for deep-out-of-the-money and deep-in-the-money options, and tends to be higher in the at-the-money condition.

[[INSERT TABLE 3 ]]

\footnotetext{
${ }^{34}$ The MSE measure is a common estimator for option mispricing in the literature. See for example Chu and Freund (1996), Christoffersen and Jacobs (2004), Bakshi, Cao, and Chen (1997), Dumas, Fleming, and Whaley (1998), Heston (1997), Liu and Shen (2008) and others.
} 
Table 4 shows the improvement (in percentages) in the MSE estimation of the SI model relative to the $\mathrm{BS}$ model. Panel A presents the improvement for call options and Panel B presents the improvement for put options. These differences (in percentages) are obtained by dividing the difference in the MSE of the models by the MSE of the BS model, across moneyness and time to maturity. Looking at the total sample, the SI model yields an average improvement in MSE of $29.51 \%$ for call options and $19.69 \%$ for put options. For both call and put options, the improvement is more significant the longer the time to maturity of the option, indicating the importance of changes in the interest rate for long-term options. These findings are highly relevant for long-term call options, such as employee stock options, and for the accuracy of accounting reports. There is no clear tendency for the MSE to improve across moneyness, except for options with 180 days or more to maturity. In this category of maturity, the improvement in the MSE increases the more the call option is out of the money and as the more the put option is in the money.

\section{[[INSERT TABLE 4 ]]}

Table 5 presents the statistical significance of the difference in pricing errors between any two models $i$ and $j$ by adopting the $t$-statistic test of the sample differences in daily mean squared errors, following Huang and $\mathrm{Wu}$ (2004). The $t$-value is calculated by

$$
t_{\text {statistic }}=\frac{\overline{M S E}_{i}-\overline{M S E}_{j}}{\operatorname{stdev}\left(\overline{M S E}_{i}-\overline{M S E}_{j}\right)},
$$

where the overline on the MSE denotes the sample average and $\operatorname{stdev}(\cdot)$ denotes the standard error of the sample mean difference. We set model $i$ to be the BS model and 
model $j$ to be the SI model. A positive $t$-value in this test implies that the MSE of the SI model is statistically more significant than that of the BS model and vice versa.

Since the $t$-statistic uses the sample average of the daily MSEs, we first group the daily MSEs and report the sample size across moneyness and maturity for both call and put options in Panel A. Pursuant to Table 2, the most inactive group, in terms of moneyness and maturity, is the group of in-the-money call contracts with 120 to 180 days to expiration. Out-of-the-money call and put options are more tradable than their in-themoney counterparts.

Panel B in Table 5 presents the statistical significance of the SI model relative to the BS model. In call options, the SI model provides significantly lower MSE values, in all categories across moneyness and maturity, compared to the BS model, except for deep-out-of-the-money options with 120 days or less to maturity. Specifically, the SI model yields a significant improvement in the MSE of call options with 120 days or more to maturity and in call options with moneyness of 0.97 or higher. Regarding put options, the SI model also yields significantly lower MSE values in all categories across moneyness and maturity than the BS model. Here, the only exception is for in-themoney put options with 120 days or less to maturity, where the BS performs better, though not significantly better. Specifically, the SI model yields a significant improvement in MSE of put options with 120 days or more to maturity, and in put options with moneyness of 0.97 or higher.

[[INSERT TABLE 5 ]] 


\section{Conclusions}

This paper extends the Black-Scholes European option pricing model to the case of stochastic Gaussian interest rates. We prove a closed-form solution for option pricing under the term structure models of Vasicek (1977) and Merton (1973). We show that our model preserves the properties of non-arbitrage pricing, and when the interest rate is nonstochastic our formulas for both call and put options collapse to the BS expression. Since stochastic interest rate constitutes an additional source of risk not priced by the BS, in most cases options are more under-priced in the BS model than in our generalized model.

We compare our SI model to the BS model using sample data on S\&P 500 index options. Our empirical results support the expected pricing improvement of the SI model. They present a significant improvement in call and put pricing using the MSE criterion as the measure of accuracy: the magnitude of this improvement is a function of the option's time to maturity, the greatest improvement being obtained for around-themoney short-term options. The SI model has implications for pricing options with no market value, and is especially useful for long-term options, such as employee stock option pricing, which must be accurately priced in financial reports. 


\section{References}

Amin, K. I., and R. A. Jarrow. "Pricing Options on Risky Assets in a Stochastic Interest Rate Economy." Mathematical Finance, 2 (1992), 217-237.

Amin, K. I., and V. K. Ng. "Inferring Future Volatility from the Information in Implied Volatility in Eurodollar Options: A New Approach." Review of Financial Studies, 10 (1997), 333-367.

Bailey, W., and R. M. Stulz. "The Pricing of Stock Index Options in a General Equilibrium Model." Journal of Financial and Quantitative Analysis, 24 (1989), 112.

Bakshi, G.; C. Cao; and Z. Chen. "Empirical Performance of Alternative Option Pricing Models." Journal of Finance, 52 (1997), 2003-2049.

Bakshi, G. S., and Z. Chen. "An Alternative Valuation Model for Contingent Claims." Journal of Financial Economics, 44 (1997a), 123-165.

Bakshi, G. S., and Z. Chen. "Equilibrium Valuation of Foreign Exchange Claims." Journal of Finance, 52 (1997b), 799-826.

Black, F., and P. Karasinski. "Bond and Option Pricing when Short Rates are Lognormal." Financial Analysts Journal, 47 (1991), 52-59.

Black, F., and M. Scholes. "The Pricing of Options and Corporate Liabilities." Journal of Political Economy, 81 (1973), 637-654.

Brennan, M., and E. Schwartz. "An Equilibrium Model of Bond Pricing and a Test of Market Efficiency." Journal of Financial and Quantitative Analysis, 17 (1982), 301329.

Brennan, M. J., and E. S. Schwartz. "Savings Bonds, Retractable Bonds and Callable 
Bonds." Journal of Financial Economics, 5 (1977), 67-88.

Brenner, M.; G. Courtandon; and M. Subrahmanyam. "Interest Rate Uncertainty and the Valuation of Stock Index Options." Working paper New York University Salomon Center, (1987).

Chan, K.; G. Karolyi; F. Longstaff; and A. Sanders. "An Empirical Comparison of Alternative Models of the Short-Term Interest Rate." Journal of Finance, 47 (1992), $1209-1227$.

Chen, R. "Pricing Stock and Bond Options when the Default-Free Rate is Stochastic: A Comment." Journal of Financial and Quantitative Analysis, 26 (1991), 433-434.

Christoffersen, P., and K. Jacobs. "Which GARCH Model for Option Valuation?" Management Science, 50 (2004), 1204-1221.

Chu, S., and S. Freund. "Volatility Estimation for Stock Index Options: A GARCH Approach." Quarterly Review of Economics and Finance, 36 (1996), 431-450.

Connolly, R.; C. Stivers; and L. Sun. "Commonality in the Time-Variation of StockStock and Stock-Bond Return Comovements." Journal of Financial Markets, 10 (2007), 192-218.

Cox, J.; J. Ingersoll Jr; and S. Ross. "A Theory of the Term Structure of Interest Rates." Econometrica, 53 (1985), 385-407.

Dietrich-Campbell, B., and E. Schwartz. "Valuing Debt Options: Empirical Evidence." Journal of Financial Economics, 16 (1986), 321-343.

Dothan, L. U. "On the Term Structure of Interest Rates." Journal of Financial Economics, 6 (1978), 59-69.

Dumas, B.; J. Fleming; and R. Whaley. "Implied Volatility Functions: Empirical Tests." 
Journal of Finance, 53 (1998), 2059-2106.

Fama, E. "The Information in the Term Structure." Journal of Financial Economics, 13 (1984), 509-528.

Fleming, J. "The Quality of Market Volatility Forecasts Implied by S\&P 100 Index Option Prices." Journal of Empirical Finance, 5 (1998), 317-345.

Goldstein, R., and F. Zapatero. "General Equilibrium with Constant Relative Risk Aversion and Vasicek Interest Rates." Mathematical Finance, 6 (1996), 331-340.

Haug, E. G. The Complete Guide to Option Pricing Formulas, $2^{\text {nd }}$ Edition (2007), McGraw-Hill, New York.

Heath, D.; R. Jarrow; and A. Morton. "Bond Pricing and the Term Structure of Interest Rates: A New Methodology for Contingent Claims valuation." Econometrica, 60 (1992), 77-105.

Heston, S., and S. Nandi. "A Closed-Form GARCH Option Pricing Model." Working paper 97-9 (1997), Federal Reserve Bank of Atlanta.

Ho, T.; R. C. Stapleton; and M. G. Subrahmanyam. "The Valuation of American Options with Stochastic Interest Rates: A Generalization of the Geske-Johnson Technique." Journal of Finance, 52 (1997), 827-840.

Ho, T. S. Y., and S. B. Lee. "Term Structure Movements and Pricing Interest Rate Contingent Claims." Journal of Finance, 41 (1986), 1011-1029.

Hsieh, K., and P. Ritchken. "An Empirical Comparison of GARCH Option Pricing Models." Review of Derivatives Research, 8 (2005), 129-150.

Huang, J., and L. Wu. "Specification Analysis of Option Pricing Models Based on Time Changed Lévy Processes." Journal of Finance, 59 (2004), 1405-1440. 
Hull, J. Options, Futures and Other Derivatives, $7^{\text {th }}$ Edition, Pearson Prentice Hall (2009).

Kim, Y.J. "Option Pricing under Stochastic Interest Rates: An Empirical Investigation." Asia-Pasific Financial Markets, 9 (2002), 23-44.

Liu, X., and L. Shen. "An Empirical Investigation of Option Pricing Models." Working paper (2008), University of Essex.

Lucas Jr, R. E. "Asset Prices in an Exchange Economy." Econometrica, 46 (1978), 14291445.

Merton, R. "Theory of Rational Option Pricing." The Bell Journal of Economics and Management Science, 4 (1973), 141-183.

Miltersen, K. R., and E. S. Schwartz. "Pricing of Options on Commodity Futures with Stochastic Term Structures of Convenience Yields and Interest rates." Journal of Financial and Quantitative Analysis, 33 (1998), 33-59.

Nowman, K. B. "Gaussian Estimation of Single-Factor Continuous Time Models of the Term Structure of Interest Rates." Journal of Finance, 52 (1997), 1695-1706.

Ogden, J. "An Analysis of Yield Curve Notes." Journal of Finance, 42 (1987), 99-110.

Rabinovitch, R. "Pricing Stock and Bond Options when the Default-Free Rate is Stochastic." Journal of Financial and Quantitative Analysis, 24 (1989), 447-457.

Rindell, K. "Pricing of Index Options when Interest Rates are Stochastic: An Empirical Test." Journal of Banking and Finance, 19 (1995), 785-802.

Rubinstein, M. "On the Accounting Valuation of Employee Stock Options." The Journal of Derivatives, 3 (1995), 8-24.

Sanders, A., and H. Unal. "On the Intertemporal Behavior of the Short-Term Rate of 
Interest." Journal of Financial and Quantitative Analysis, 23 (1988), 417-423.

Svensson, S., and S. Dietzsch. "The Correlation Between Treasury Securities and the Stock Market: A study of Explanatory Variables." In School of Economics and Management. Lund: Lund University (2009).

Vasicek, O. "An Equilibrium Characterization of the Term Structure." Journal of Financial Economics, 5 (1977), 177-188. 


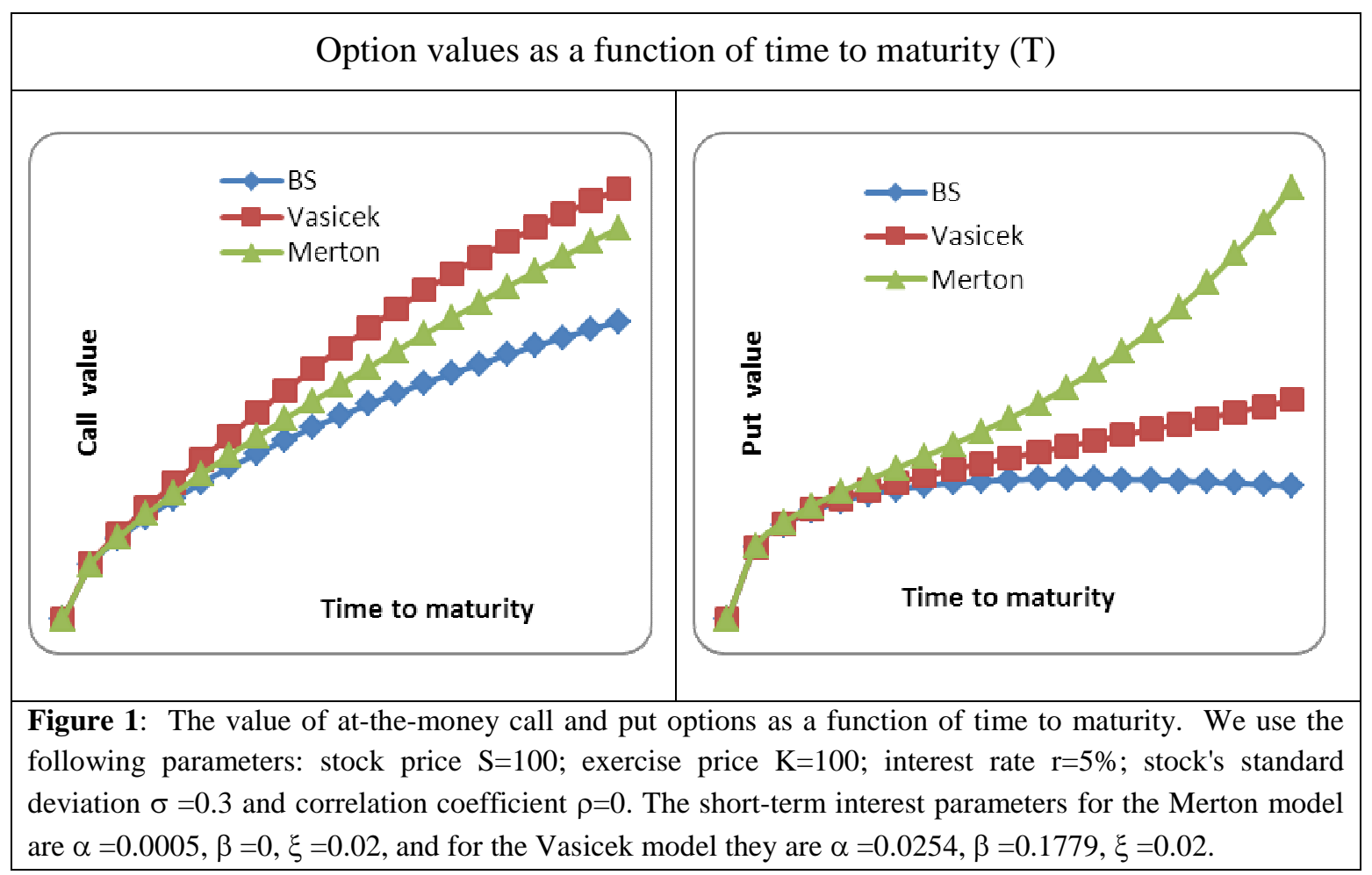




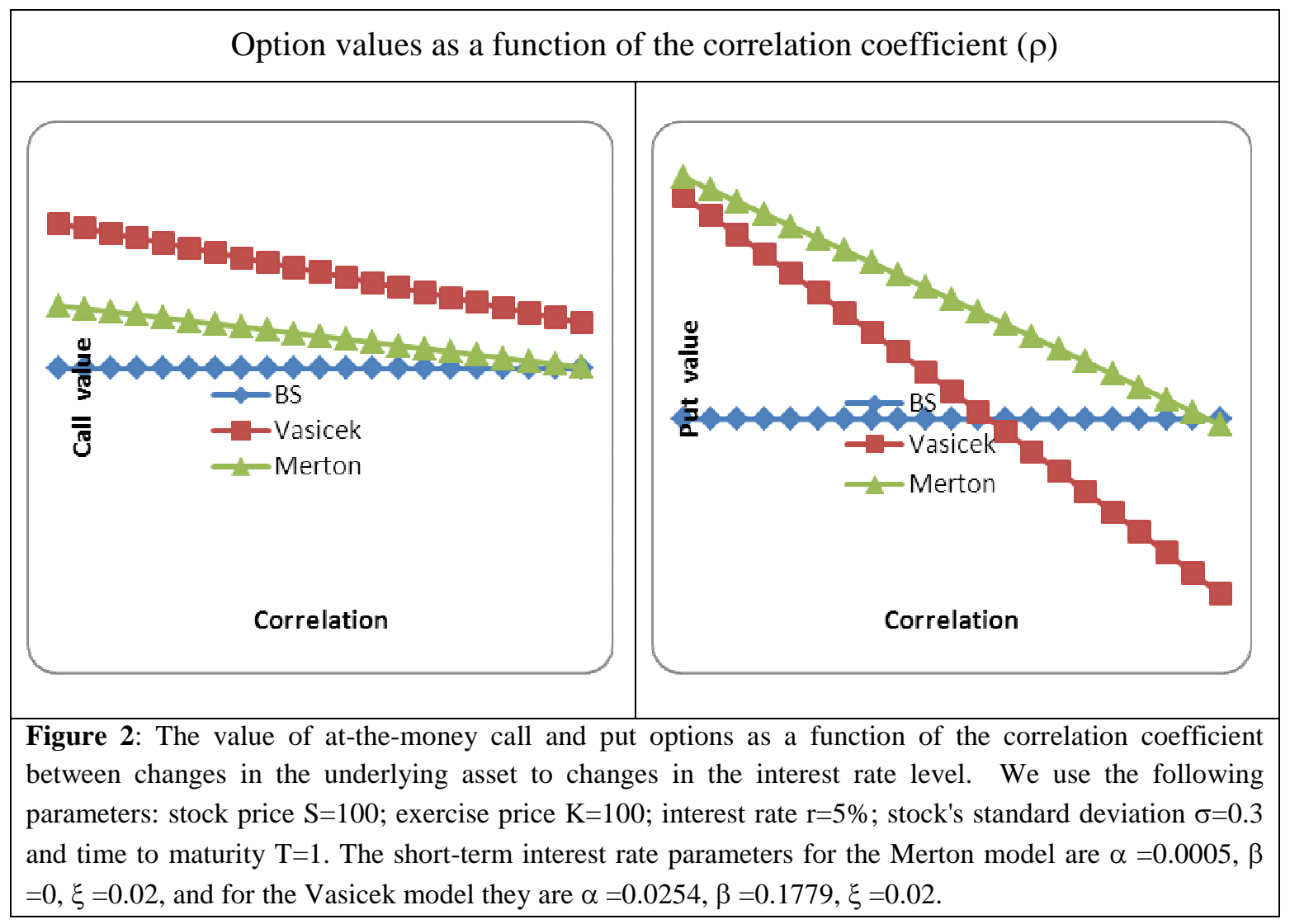




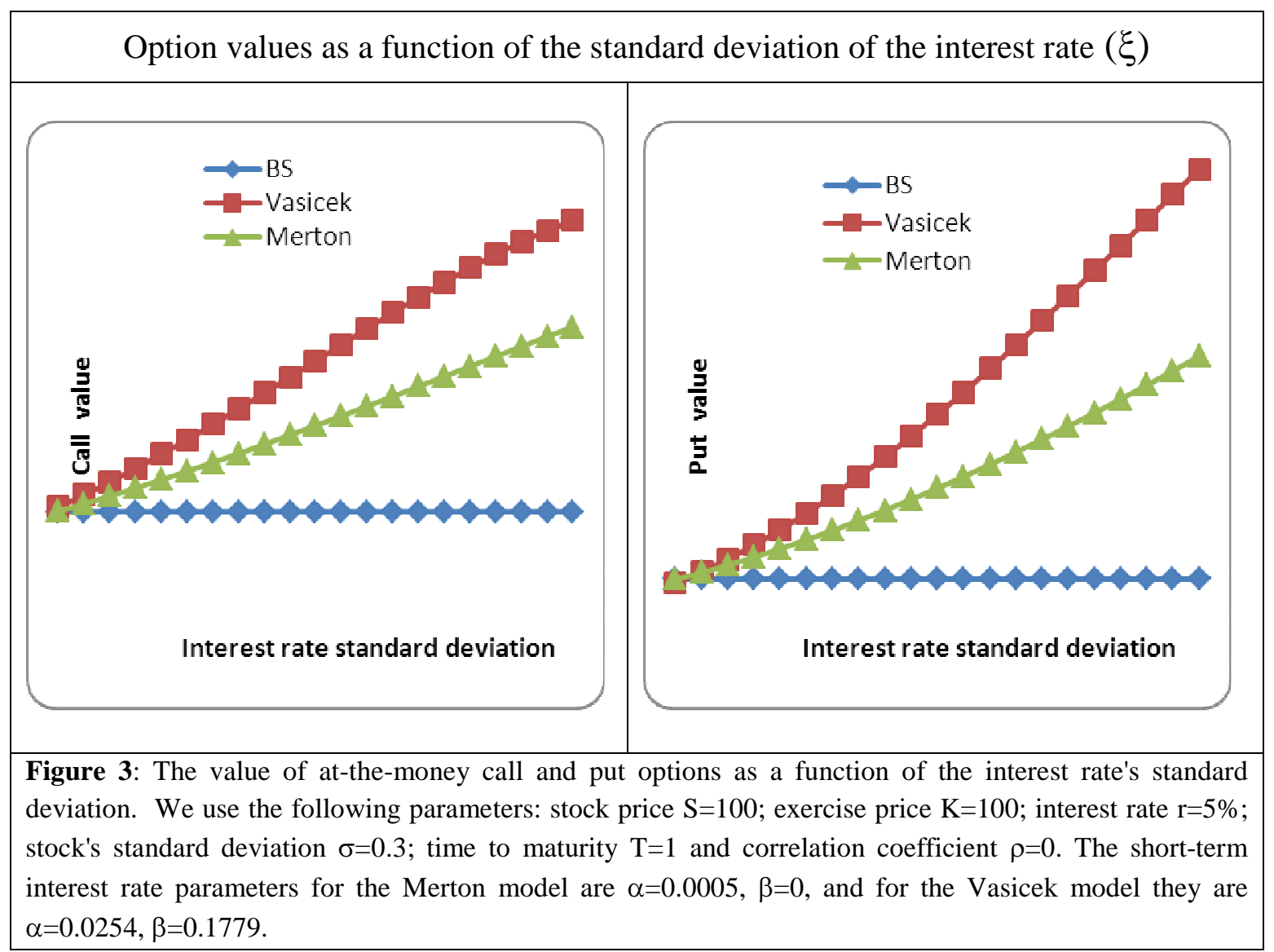




\section{Table 1}

\section{Parameter estimation of the Merton and Vasicek models of short-term interest rate}

This table depicts the estimated parameters of the Merton and Vasicek models of short-term interest rate. The estimation uses the yield to maturity of one-month T-bills reported by CRSP's monthly treasury section. The estimation horizon is monthly data covering the period from January 1960 to December 2009, providing 600 observations in total. For each month the selected T-bill is the one closest to 30 days to maturity in absolute values. The parameters are estimated using an OLS regression.

\begin{tabular}{|c|c|c|c|c|}
\hline & \multicolumn{4}{|c|}{$\begin{array}{c}\text { Parameter } \\
\text { (t-stat) }\end{array}$} \\
\hline Model & $\alpha$ & $\beta$ & $\sigma^{2}$ & $R^{2}$ \\
\hline Merton & $\begin{array}{c}-0.00062 \\
(-0.204)\end{array}$ & -- & 0.000050 & 0 \\
\hline Vasicek & $\begin{array}{c}0.001695 \\
(2.672)\end{array}$ & $\begin{array}{c}-0.034883 \\
(-3.143)\end{array}$ & 0.000055 & 0.01628 \\
\hline
\end{tabular}


Table 2

Number of call and put contracts across moneyness and maturity

This table reports descriptive statistics on call and put contracts on the S\&P 500 index for the period from January 3, 2005 to December 30, 2006. Each sample is divided into four maturity bins and six moneyness bins.

\begin{tabular}{|c|c|c|c|c|c|}
\hline \multicolumn{6}{|c|}{ A. Call } \\
\hline & \multicolumn{5}{|c|}{ Number of days to expiration (D) } \\
\hline Moneyness (S/K) & $D<60$ & $60 \leq \mathrm{D}<120$ & $120 \leq \mathrm{D}<180$ & $D \geq 180$ & Total sample \\
\hline $\mathrm{S} / \mathrm{K}<0.94$ & 310 & 723 & 566 & 2,235 & 3,834 \\
\hline $0.94 \leq \mathrm{S} / \mathrm{K}<0.97$ & 3,224 & 1,247 & 390 & 683 & 5,544 \\
\hline $0.97 \leq \mathrm{S} / \mathrm{K}<\mathbf{1 . 0 0}$ & 5,233 & 1,730 & 439 & 1,169 & 8,571 \\
\hline $1.00 \leq \mathrm{S} / \mathrm{K}<\mathbf{1 . 0 3}$ & 2,773 & 712 & 217 & 787 & 4,489 \\
\hline $1.03 \leq \mathrm{S} / \mathrm{K}<1.06$ & 669 & 170 & 63 & 185 & 1,087 \\
\hline $\mathrm{S} / \mathrm{K} \geq \mathbf{1 . 0 6}$ & 672 & 279 & 76 & 214 & 1,241 \\
\hline Total sample & 12,881 & 4,861 & 1,751 & 5,273 & 24,766 \\
\hline \multicolumn{6}{|c|}{ B. Put } \\
\hline & \multicolumn{5}{|c|}{ Number of days to expiration (D) } \\
\hline Moneyness (S/K) & $\mathrm{D}<60$ & $60 \leq D<120$ & $120 \leq \mathrm{D}<180$ & $D \geq 180$ & Total sample \\
\hline $\mathrm{S} / \mathrm{K}<0.94$ & 244 & 230 & 113 & 775 & 1,362 \\
\hline $0.94 \leq \mathrm{S} / \mathrm{K}<0.97$ & 534 & 188 & 168 & 746 & 1,636 \\
\hline $0.97 \leq \mathrm{S} / \mathrm{K}<\mathbf{1 . 0 0}$ & 3,545 & 1,387 & 434 & 1,394 & 6,760 \\
\hline $1.00 \leq \mathrm{S} / \mathrm{K}<1.03$ & 4,933 & 1,398 & 472 & 1,095 & 7,898 \\
\hline $1.03 \leq \mathrm{S} / \mathrm{K}<1.06$ & 4,090 & 1,071 & 412 & 857 & 6,430 \\
\hline $\mathrm{S} / \mathrm{K} \geq 1.06$ & 5,068 & 2,495 & 1,333 & 3,855 & 12,751 \\
\hline Total sample & 18,414 & 6,769 & 2,932 & 8,722 & 36,837 \\
\hline
\end{tabular}


Table 3

MSE estimation

This table reports the MSE estimation of call and put options contracts using the SI model and the BS model. The underlying asset is the S\&P 500 index. The option's sample period is from January 3, 2005 to December 30, 2006. The option's market prices are calculated using the mid-point of the end-of-the-day bid-ask quotes. We calculate the SE of each contract and then calculate a mean for all the contracts across moneyness and maturity.

\begin{tabular}{|c|c|c|c|c|c|c|}
\hline \multicolumn{7}{|c|}{ A. MSE of the SI model } \\
\hline & \multicolumn{6}{|c|}{ Number of days to expiration (D) } \\
\hline Moneyness (S/K) & $\begin{array}{c}\text { Option } \\
\text { type }\end{array}$ & $\mathrm{D}<60$ & $60 \leq D<120$ & $120 \leq \mathrm{D}<180$ & $\mathrm{D} \geq \mathbf{1 8 0}$ & $\begin{array}{c}\text { Total } \\
\text { sample }\end{array}$ \\
\hline $\mathrm{S} / \mathrm{K}<0.94$ & $\begin{array}{l}\text { Call } \\
\text { Put }\end{array}$ & $\begin{array}{l}0.42 \\
2.81\end{array}$ & $\begin{array}{c}1.4 \\
3.96\end{array}$ & $\begin{array}{l}3.11 \\
9.79\end{array}$ & $\begin{array}{c}43.08 \\
202.12\end{array}$ & $\begin{array}{c}25.87 \\
117.00\end{array}$ \\
\hline $0.94 \leq \mathrm{S} / \mathrm{K}<0.97$ & $\begin{array}{l}\text { Call } \\
\text { Put }\end{array}$ & $\begin{array}{l}1.85 \\
6.36\end{array}$ & $\begin{array}{c}5.44 \\
23.44\end{array}$ & $\begin{array}{c}15.3 \\
45.28\end{array}$ & $\begin{array}{l}137.69 \\
460.81\end{array}$ & $\begin{array}{c}20.34 \\
219.54\end{array}$ \\
\hline $0.97 \leq \mathrm{S} / \mathrm{K}<1.00$ & $\begin{array}{l}\text { Call } \\
\text { Put }\end{array}$ & $\begin{array}{l}4.51 \\
7.64\end{array}$ & $\begin{array}{l}16.08 \\
28.53\end{array}$ & $\begin{array}{l}48.87 \\
75.66\end{array}$ & $\begin{array}{l}275.43 \\
315.96\end{array}$ & $\begin{array}{l}46.07 \\
79.87\end{array}$ \\
\hline $1.00 \leq \mathrm{S} / \mathrm{K}<\mathbf{1 . 0 3}$ & $\begin{array}{l}\text { Call } \\
\text { Put }\end{array}$ & $\begin{array}{l}6.55 \\
9.94\end{array}$ & $\begin{array}{l}27.67 \\
38.25\end{array}$ & $\begin{array}{c}63.48 \\
102.37\end{array}$ & $\begin{array}{l}297.43 \\
327.89\end{array}$ & $\begin{array}{l}63.74 \\
64.56\end{array}$ \\
\hline $1.03 \leq \mathrm{S} / \mathrm{K}<1.06$ & $\begin{array}{l}\text { Call } \\
\text { Put }\end{array}$ & $\begin{array}{l}8.31 \\
9.11\end{array}$ & $\begin{array}{l}34.63 \\
42.59\end{array}$ & $\begin{array}{c}77.61 \\
107.57\end{array}$ & $\begin{array}{l}275.79 \\
314.89\end{array}$ & $\begin{array}{l}61.96 \\
61.75\end{array}$ \\
\hline $\mathrm{S} / \mathrm{K} \geq \mathbf{1 . 0 6}$ & $\begin{array}{l}\text { Call } \\
\text { Put }\end{array}$ & $\begin{array}{l}4.72 \\
3.88\end{array}$ & $\begin{array}{l}12.7 \\
15.8\end{array}$ & $\begin{array}{l}48.94 \\
44.91\end{array}$ & $\begin{array}{l}184.53 \\
142.33\end{array}$ & $\begin{array}{l}40.23 \\
52.36\end{array}$ \\
\hline Total sample & $\begin{array}{l}\text { Call } \\
\text { Put }\end{array}$ & $\begin{array}{l}4.39 \\
7.45\end{array}$ & $\begin{array}{l}13.32 \\
27.09\end{array}$ & $\begin{array}{l}29.45 \\
66.18\end{array}$ & $\begin{array}{l}158.79 \\
242.88\end{array}$ & $\begin{array}{l}40.79 \\
71.48\end{array}$ \\
\hline \multicolumn{7}{|c|}{ B. MSE of the BS model } \\
\hline & \multicolumn{6}{|c|}{ Number of days to expiration (D) } \\
\hline Moneyness (S/K) & $\begin{array}{c}\text { Option } \\
\text { type }\end{array}$ & $\mathrm{D}<60$ & $60 \leq D<120$ & $120 \leq \mathrm{D}<180$ & $\mathrm{D} \geq \mathbf{1 8 0}$ & $\begin{array}{c}\text { Total } \\
\text { sample }\end{array}$ \\
\hline $\mathrm{S} / \mathrm{K}<0.94$ & $\begin{array}{l}\text { Call } \\
\text { Put }\end{array}$ & $\begin{array}{l}0.41 \\
2.81\end{array}$ & $\begin{array}{l}1.35 \\
3.97\end{array}$ & $\begin{array}{c}3.18 \\
10.41\end{array}$ & $\begin{array}{c}81.8 \\
358.09\end{array}$ & $\begin{array}{l}48.44 \\
205.8\end{array}$ \\
\hline $0.94 \leq \mathrm{S} / \mathrm{K}<0.97$ & $\begin{array}{l}\text { Call } \\
\text { Put }\end{array}$ & $\begin{array}{l}1.83 \\
6.38\end{array}$ & $\begin{array}{c}5.49 \\
23.99\end{array}$ & $\begin{array}{l}16.93 \\
49.08\end{array}$ & $\begin{array}{c}209.9 \\
715.49\end{array}$ & $\begin{array}{c}29.34 \\
336.14\end{array}$ \\
\hline $0.97 \leq \mathrm{S} / \mathrm{K}<1.00$ & $\begin{array}{l}\text { Call } \\
\text { Put }\end{array}$ & $\begin{array}{l}4.52 \\
7.69\end{array}$ & $\begin{array}{l}16.68 \\
29.42\end{array}$ & $\begin{array}{l}53.35 \\
81.47\end{array}$ & $\begin{array}{l}407.79 \\
408.57\end{array}$ & $\begin{array}{l}64.48 \\
99.55\end{array}$ \\
\hline $1.00 \leq \mathrm{S} / \mathrm{K}<1.03$ & $\begin{array}{l}\text { Call } \\
\text { Put }\end{array}$ & $\begin{array}{c}6.61 \\
10.03\end{array}$ & $\begin{array}{c}28.6 \\
39.26\end{array}$ & $\begin{array}{c}68.35 \\
108.37\end{array}$ & $\begin{array}{l}430.92 \\
405.87\end{array}$ & $\begin{array}{l}87.47 \\
75.96\end{array}$ \\
\hline $1.03 \leq \mathrm{S} / \mathrm{K}<1.06$ & $\begin{array}{l}\text { Call } \\
\text { Put }\end{array}$ & $\begin{array}{l}8.35 \\
9.16\end{array}$ & $\begin{array}{l}35.44 \\
43.34\end{array}$ & $\begin{array}{l}82.06 \\
112.1\end{array}$ & $\begin{array}{l}348.53 \\
368.60\end{array}$ & $\begin{array}{l}74.76 \\
69.35\end{array}$ \\
\hline $\mathrm{S} / \mathrm{K} \geq 1.06$ & $\begin{array}{l}\text { Call } \\
\text { Put }\end{array}$ & $\begin{array}{l}4.73 \\
3.88 \\
\end{array}$ & $\begin{array}{c}12.8 \\
15.92 \\
\end{array}$ & $\begin{array}{l}50.53 \\
45.84 \\
\end{array}$ & $\begin{array}{l}222.84 \\
158.10 \\
\end{array}$ & $\begin{array}{l}46.96 \\
57.25 \\
\end{array}$ \\
\hline Total sample & $\begin{array}{l}\text { Call } \\
\text { Put }\end{array}$ & $\begin{array}{l}4.41 \\
7.49\end{array}$ & $\begin{array}{c}13.7 \\
27.67\end{array}$ & $\begin{array}{l}31.79 \\
69.31\end{array}$ & $\begin{array}{l}237.85 \\
315.36\end{array}$ & $\begin{array}{l}57.87 \\
89.01\end{array}$ \\
\hline
\end{tabular}


Table 4

Differences in MSE estimations between the SI model and the BS model

This table reports the difference (in percentages) between the MSE estimations of the SI model and the BS model, for call and put options contracts across moneyness and maturity. The underlying asset is the S\&P 500 index. The option's sample period is from January 3, 2005 to December 30, 2006. The option's market prices are calculated using the mid-point of the end-of-the-day bid-ask quotes.

\begin{tabular}{|c|c|c|c|c|c|}
\hline \multicolumn{6}{|c|}{ A. Call } \\
\hline \multirow[b]{2}{*}{ Moneyness (S/K) } & \multicolumn{5}{|c|}{ Number of days to expiration (D) } \\
\hline & $\mathrm{D}<60$ & $60 \leq \mathrm{D}<120$ & $120 \leq \mathrm{D}<180$ & $\mathrm{D} \geq 180$ & Total sample \\
\hline $\mathrm{S} / \mathrm{K}<0.94$ & $-2.44 \%$ & $-3.70 \%$ & $2.20 \%$ & $47.33 \%$ & $46.59 \%$ \\
\hline $0.94 \leq \mathrm{S} / \mathrm{K}<0.97$ & $-1.22 \%$ & $0.55 \%$ & $9.63 \%$ & $34.40 \%$ & $30.67 \%$ \\
\hline $0.97 \leq \mathrm{S} / \mathrm{K}<\mathbf{1 . 0 0}$ & $0.22 \%$ & $3.60 \%$ & $8.40 \%$ & $32.46 \%$ & $28.55 \%$ \\
\hline $1.00 \leq \mathrm{S} / \mathrm{K}<1.03$ & $0.91 \%$ & $3.25 \%$ & $7.13 \%$ & $30.85 \%$ & $27.13 \%$ \\
\hline $1.03 \leq \mathrm{S} / \mathrm{K}<1.06$ & $0.48 \%$ & $2.29 \%$ & $5.42 \%$ & $20.87 \%$ & $17.12 \%$ \\
\hline $\mathrm{S} / \mathrm{K} \geq \mathbf{1 . 0 6}$ & $0.21 \%$ & $0.78 \%$ & $3.15 \%$ & $17.19 \%$ & $14.33 \%$ \\
\hline Total sample & $0.45 \%$ & $2.77 \%$ & $7.36 \%$ & $33.24 \%$ & $29.51 \%$ \\
\hline \multicolumn{6}{|c|}{ B. Put } \\
\hline & \multicolumn{5}{|c|}{ Number of days to expiration (D) } \\
\hline Moneyness (S/K) & $D<60$ & $60 \leq D<120$ & $120 \leq \mathrm{D}<180$ & $D \geq 180$ & Total sample \\
\hline $\mathrm{S} / \mathrm{K}<0.94$ & $0.00 \%$ & $0.25 \%$ & $5.96 \%$ & $43.56 \%$ & $43.15 \%$ \\
\hline $0.94 \leq \mathrm{S} / \mathrm{K}<\mathbf{0 . 9 7}$ & $0.31 \%$ & $2.29 \%$ & $7.74 \%$ & $35.60 \%$ & $34.69 \%$ \\
\hline $0.97 \leq \mathrm{S} / \mathrm{K}<\mathbf{1 . 0 0}$ & $0.65 \%$ & $3.03 \%$ & $7.13 \%$ & $22.67 \%$ & $19.77 \%$ \\
\hline $1.00 \leq \mathrm{S} / \mathrm{K}<1.03$ & $0.90 \%$ & $2.57 \%$ & $5.54 \%$ & $19.21 \%$ & $15.01 \%$ \\
\hline $1.03 \leq \mathrm{S} / \mathrm{K}<1.06$ & $0.55 \%$ & $1.73 \%$ & $4.04 \%$ & $14.57 \%$ & $10.96 \%$ \\
\hline $\mathrm{S} / \mathrm{K} \geq \mathbf{1 . 0 6}$ & $0.00 \%$ & $0.75 \%$ & $2.03 \%$ & $9.97 \%$ & $8.54 \%$ \\
\hline Total sample & $0.53 \%$ & $2.10 \%$ & $4.52 \%$ & $22.98 \%$ & $19.69 \%$ \\
\hline
\end{tabular}


Table 5

$t$-statistic of the MSE differences between the SI model and the BS model

This table reports the $t$-statistics of the MSE differences between the SI model and the BS model, for call and put option contracts across moneyness and maturity. The underlying asset is the S\&P 500 index. The option's sample period is from January 3, 2005 to December 30, 2006. The option's market prices are calculated using the mid-point of the bid-ask quotes. The $t$-statistic measure is based on Huang and $\mathrm{Wu}$ (2004). For each test (Model $i$ - Model $j$ ), a $t$-value greater than 1.645 implies that the mean squared pricing error from model $i$ is significantly larger than the mean squared error from model $j$. A $t$-value less than -1.645 implies the opposite, i.e. model $j$ 's MSE is significantly larger than model $i$ 's MSE.

\begin{tabular}{|c|c|c|c|c|c|c|}
\hline \multicolumn{7}{|c|}{ A. Number of days in the sample } \\
\hline & \multicolumn{6}{|c|}{ Number of days to expiration (D) } \\
\hline Moneyness (S/K) & $\begin{array}{c}\text { Option } \\
\text { type }\end{array}$ & $\mathbf{D}<60$ & $60 \leq \mathrm{D}<120$ & $120 \leq \mathrm{D}<180$ & $\mathbf{D} \geq 180$ & $\begin{array}{c}\text { Total } \\
\text { sample }\end{array}$ \\
\hline $\mathrm{S} / \mathrm{K}<0.94$ & $\begin{array}{l}\text { Call } \\
\text { Put }\end{array}$ & $\begin{array}{l}199 \\
173\end{array}$ & $\begin{array}{l}363 \\
159\end{array}$ & $\begin{array}{c}286 \\
85\end{array}$ & $\begin{array}{l}493 \\
325\end{array}$ & $\begin{array}{l}499 \\
420\end{array}$ \\
\hline $0.94 \leq \mathrm{S} / \mathrm{K}<0.97$ & $\begin{array}{l}\text { Call } \\
\text { Put }\end{array}$ & $\begin{array}{l}500 \\
258\end{array}$ & $\begin{array}{l}465 \\
150\end{array}$ & $\begin{array}{l}276 \\
140\end{array}$ & $\begin{array}{l}375 \\
384\end{array}$ & $\begin{array}{l}500 \\
460\end{array}$ \\
\hline $0.97 \leq \mathrm{S} / \mathrm{K}<\mathbf{1 . 0 0}$ & $\begin{array}{l}\text { Call } \\
\text { Put }\end{array}$ & $\begin{array}{l}500 \\
500 \\
\end{array}$ & $\begin{array}{l}464 \\
439\end{array}$ & $\begin{array}{l}300 \\
313 \\
\end{array}$ & $\begin{array}{l}436 \\
482 \\
\end{array}$ & $\begin{array}{l}500 \\
500\end{array}$ \\
\hline $1.00 \leq \mathrm{S} / \mathrm{K}<\mathbf{1 . 0 3}$ & $\begin{array}{l}\text { Call } \\
\text { Put }\end{array}$ & $\begin{array}{l}498 \\
500\end{array}$ & $\begin{array}{l}362 \\
470\end{array}$ & $\begin{array}{l}182 \\
317\end{array}$ & $\begin{array}{l}353 \\
463\end{array}$ & $\begin{array}{l}499 \\
500\end{array}$ \\
\hline $1.03 \leq \mathrm{S} / \mathrm{K}<1.06$ & $\begin{array}{l}\text { Call } \\
\text { Put }\end{array}$ & $\begin{array}{l}357 \\
500\end{array}$ & $\begin{array}{l}135 \\
460\end{array}$ & $\begin{array}{c}59 \\
313\end{array}$ & $\begin{array}{l}134 \\
427\end{array}$ & $\begin{array}{l}412 \\
500\end{array}$ \\
\hline $\mathrm{S} / \mathrm{K} \geq \mathbf{1 . 0 6}$ & $\begin{array}{l}\text { Call } \\
\text { Put }\end{array}$ & $\begin{array}{l}320 \\
500 \\
\end{array}$ & $\begin{array}{l}173 \\
469 \\
\end{array}$ & $\begin{array}{c}59 \\
334 \\
\end{array}$ & $\begin{array}{l}145 \\
495 \\
\end{array}$ & $\begin{array}{l}422 \\
500 \\
\end{array}$ \\
\hline Total sample & $\begin{array}{l}\text { Call } \\
\text { Put }\end{array}$ & $\begin{array}{l}500 \\
500 \\
\end{array}$ & $\begin{array}{l}476 \\
476 \\
\end{array}$ & $\begin{array}{l}337 \\
340 \\
\end{array}$ & $\begin{array}{l}500 \\
500 \\
\end{array}$ & $\begin{array}{l}500 \\
500 \\
\end{array}$ \\
\hline \multicolumn{7}{|c|}{ B. Pairwise $t$-statistic for model comparisons } \\
\hline & \multicolumn{6}{|c|}{ Number of days to expiration (D) } \\
\hline Moneyness (S/K) & $\begin{array}{c}\text { Option } \\
\text { type }\end{array}$ & $\mathrm{D}<60$ & $60 \leq \mathrm{D}<120$ & $120 \leq \mathrm{D}<180$ & $D \geq 180$ & $\begin{array}{c}\text { Total } \\
\text { sample }\end{array}$ \\
\hline $\mathrm{S} / \mathrm{K}<0.94$ & $\begin{array}{l}\text { Call } \\
\text { Put }\end{array}$ & $\begin{array}{l}-7.08 * * \\
-1.56\end{array}$ & $\begin{array}{l}-8.92 * * \\
-0.43\end{array}$ & $\begin{array}{l}0.49 \\
4.23 * *\end{array}$ & $\begin{array}{l}15.06 * * \\
11.47 * *\end{array}$ & $\begin{array}{l}14.37 * * \\
9.66 * *\end{array}$ \\
\hline $0.94 \leq \mathrm{S} / \mathrm{K}<0.97$ & $\begin{array}{l}\text { Call } \\
\text { Put }\end{array}$ & $\begin{array}{l}-13.29 * * \\
-0.05\end{array}$ & $\begin{array}{c}0.1 \\
5.82 * *\end{array}$ & $\begin{array}{l}11.95 * * \\
13.22 * *\end{array}$ & $\begin{array}{l}11.87 * * \\
20.34 * *\end{array}$ & $\begin{array}{l}12.89 * * \\
15.19 * *\end{array}$ \\
\hline $0.97 \leq \mathrm{S} / \mathrm{K}<\mathbf{1 . 0 0}$ & $\begin{array}{l}\text { Call } \\
\text { Put }\end{array}$ & $\begin{array}{l}2.55 * * \\
7.06 * *\end{array}$ & $\begin{array}{l}17.33 * * \\
20.27 * *\end{array}$ & $\begin{array}{l}24.08 * * \\
30.11 * *\end{array}$ & $\begin{array}{l}19.8 * * \\
26.51 * *\end{array}$ & $\begin{array}{l}17.99 * * \\
24.97 * *\end{array}$ \\
\hline $1.00 \leq \mathrm{S} / \mathrm{K}<\mathbf{1 . 0 3}$ & $\begin{array}{l}\text { Call } \\
\text { Put }\end{array}$ & $\begin{array}{l}16.67 * * \\
20.85 * *\end{array}$ & $\begin{array}{l}23.94 * * \\
33.03 * *\end{array}$ & $\begin{array}{l}23.14 * * \\
35.89 * *\end{array}$ & $\begin{array}{l}16.11 * * \\
20.83 * *\end{array}$ & $\begin{array}{l}15.74 * * \\
21.24 * *\end{array}$ \\
\hline $1.03 \leq \mathrm{S} / \mathrm{K}<1.06$ & $\begin{array}{l}\text { Call } \\
\text { Put }\end{array}$ & $\begin{array}{l}14.52 * * \\
28.81 * *\end{array}$ & $\begin{array}{l}16.34 * * \\
37.88 * *\end{array}$ & $\begin{array}{l}15.09 * * \\
38.43 * *\end{array}$ & $\begin{array}{l}10.06 * * \\
18.60 * *\end{array}$ & $\begin{array}{c}7.47 * * \\
18.87 * *\end{array}$ \\
\hline $\mathrm{S} / \mathrm{K} \geq \mathbf{1 . 0 6}$ & $\begin{array}{l}\text { Call } \\
\text { Put }\end{array}$ & $\begin{array}{l}8.49 * * \\
31.91 * *\end{array}$ & $\begin{array}{c}6.52 * * \\
26.55 * *\end{array}$ & $\begin{array}{c}9.07 * * \\
23.38 * *\end{array}$ & $\begin{array}{l}5.04 * * \\
20.06 * *\end{array}$ & $\begin{array}{c}4.59 * * \\
23.57 * *\end{array}$ \\
\hline Total sample & $\begin{array}{l}\text { Call } \\
\text { Put }\end{array}$ & $\begin{array}{l}4.61 * * \\
19.04 * * \\
\end{array}$ & $\begin{array}{l}16.98 * * \\
28.86 * *\end{array}$ & $\begin{array}{l}43.43 * * \\
32.62 * * \\
\end{array}$ & $\begin{array}{l}28.36^{* *} * \\
31.6^{* *}\end{array}$ & $\begin{array}{l}29.09 * * \\
37.64 * * \\
\end{array}$ \\
\hline
\end{tabular}

$* * 99 \%$ confidence level 


\section{APPENDIX}

Lemma 1: Assume that the short-term interest rate, $r(t)$, follows the dynamics of Equation (2). Then the accumulation factor of a holding period $\tau=T-t$ is

$$
R(t, T)=e^{\int^{T} r(u) d u}=e^{A(t, T)+B(t, T) H(\tau)}
$$

with the boundary condition $R(t, t)=1$, such that if $\beta=0$ then $A(t, T)=r(t) \tau+\frac{1}{2} \alpha \tau^{2}$

and $B(t, T)=\frac{1}{\sqrt{3}} \xi \tau^{\frac{3}{2}}$, and if $\beta \neq 0$ then $A(t, T)=\frac{\alpha}{\beta} \tau+\left(r(t)-\frac{\alpha}{\beta}\right) \lambda(t, T)$ and

$B(t, T)=\frac{\xi}{\beta} \sqrt{\tau-\lambda(t, T)-\frac{\beta}{2} \lambda^{2}(t, T)}$, where $\lambda(t, T)=\frac{1}{\beta}\left(1-e^{-\beta \tau}\right) .{ }^{35}$

Proof: The proof adjusts a method of solving stochastic differential equations for the Ornstein-Uhlenbeck process combined with the stochastic Fubini theorem. We prove the lemma in two different parts, for the case where $\beta=0$ and for the case where $\beta \neq 0$.

Part $1(\beta=0)$ : Define the process $Y(u)=r(u)(T-u)$.

Applying Ito's lemma and integrating gives $\int_{t}^{T} r(u) d u=r(t)(T-t)+\int_{t}^{T}(T-u) d r(u)$.

Define the process $\Psi(t, T)=\int_{t}^{T} r(u) d u$. Thus $\Psi(t, T)=r(t)(T-t)+\int_{t}^{T}(T-u) d r(u)$.

Substituting for $d r(u)$ (Equation (2) with $\beta=0$ ) yields

$$
\Psi(t, T)=r(t)(T-t)+\frac{1}{2} \alpha(T-t)^{2}+\int_{t}^{T} \xi(T-u) d H(u) .
$$

\footnotetext{
${ }^{35}$ Note that the value assigned to $\beta$ must be a real value, $\beta \in \mathbb{R}$, such that $B(t, T)$ is well defined as a real number.
} 
Since $f(u)=\xi(T-u)$ is continuous, the variance of this Gaussian process is ${ }^{36}$

$$
V(t, T)=\int_{t}^{T} f^{2}(u) d u=\frac{1}{3}(T-t)^{3} \xi^{2}
$$

Finally, a sample path of the stochastic process $\Psi(t, T)$ is as follows:

$$
\Psi(t, T)=r(t)(T-t)+\frac{1}{2} \alpha(T-t)^{2}+\frac{1}{\sqrt{3}}(T-t)^{\frac{3}{2}} \xi H(T-t)
$$

Part $2(\beta \neq 0)$ : Define the process $Y(u)=r(u) e^{-\beta(T-u)}$, where $0 \leq u \leq T$.

Applying Ito's lemma and substituting Equation (2) for $d r(u)$ gives

$$
d Y(u)=e^{-\beta(T-u)}(\alpha d u-\beta r(u) d u+\xi d H(u)+\beta r(u) d u)=e^{-\beta(T-u)}(\alpha d u+\xi d H(u)) .
$$

Hence,

$$
r(T)=r(t) e^{-\beta(T-t)}+\frac{\alpha}{\beta}\left(1-e^{-\beta(T-t)}\right)+\int_{t}^{T} \xi e^{-\beta(T-u)} d H(u) .
$$

Defining the process $\Psi(t, T)=\int_{t}^{T} r(u) d u$ and substituting for $r(u)$ leads to

$$
\Psi(t, T)=r(t) \int_{t}^{T} e^{-\beta(T-u)} d u+\frac{\alpha}{\beta} \int_{t}^{T} d u-\frac{\alpha}{\beta} \int_{t}^{T} e^{-\beta(T-u)} d u+\xi \int_{t}^{T} \int_{t}^{u} e^{-\beta[u-x]} d H(x) d u
$$

Applying the Riemann integral to the first term of Equation (9) gives

$$
\lambda(t, T)=\int_{t}^{T} e^{-\beta(T-u)} d u=\frac{1}{\beta}\left(1-e^{-\beta(T-t)}\right) .
$$

Applying the stochastic Fubini theorem to the last term of Equation (9) gives

${ }^{36}$ If $d W$ is a standard Wiener process then for any continuous function $f:[t, T] \rightarrow \mathbb{R}$,

$$
\int_{t}^{T} f(u) d W(u) \sim \mathrm{N}\left(0, \int_{t}^{T} f^{2}(u) d u\right)
$$




$$
\int_{t}^{T} \int_{t}^{u} e^{-\beta[u-x]} d H(x) d u=\int_{t}^{T} \int_{t}^{u} e^{-\beta u} e^{\beta x} d H(x) d u=\int_{t}^{T} \lambda(x, T) d H(x) .{ }^{37}
$$

Since $f(u)=\frac{\xi}{\beta}\left(1-e^{-\beta(T-u)}\right)=\xi \lambda(u, T)$ is continuous, the variance of the process is

$$
V(t, T)=\int_{t}^{T} f^{2}(u) d u=\frac{\xi^{2}}{\beta^{2}}\left((T-t)-\lambda(t, T)-\frac{\beta}{2} \lambda^{2}(t, T)\right) .
$$

Finally, a sample path of the stochastic process $\Psi(t, T)$ is as follows:

$$
\Psi(t, T)=-\frac{\alpha}{\beta}(T-t)+\left(r(t)+\frac{\alpha}{\beta}\right) \lambda(t, T)-\frac{\xi}{\beta} \sqrt{(T-t)-\lambda(t, T)-\frac{\beta}{2} \lambda^{2}(t, T)} H(\tau),
$$

where $\lambda(t, T)=\frac{1}{\beta}\left(1-e^{-\beta(T-t)}\right)$.

Lemma 2: The excess return factor, $X(t)$, follows a geometric Brownian motion defined by the stochastic differential form

$$
d X(t)=X(t) \eta d t+X(t) v d W(t)
$$

with a drift $\eta=\mu-A_{\tau}(0, t)+\frac{1}{2} v^{2}$ and a diffusion $v^{2}=\sigma^{2}+B^{2}(0, t)-2 \rho \sigma B(0, t)$, where $d W(t)$ is a standard Wiener processes, and $A_{\tau}(t, T)$ stands for the derivative of $A(t, T)$ with respect to $\tau=T-t$.

Proof: The process $X(t, T)$ is defined as $X(t, T)=\frac{S(T)}{S(t) R(t, T)}$.

Differentiating $R(t, T)$ using Ito's lemma gives

\footnotetext{
${ }^{37}$ See Theorem IV in Protter (1990).
} 


$$
d R(t)=R(t)\left(A_{t}(t, T)+\frac{1}{2} B^{2}(t, T)\right) d t+R(t) B(t, T) d H(t) .
$$

Differentiating $X(t, T)$ using Ito's lemma, where for brevity the time descriptors are omitted, gives $d X=\frac{1}{R} d S-\frac{S}{R^{2}} d R-\frac{1}{R^{2}} d S d R+\frac{S}{R^{3}} d R d R$.

Substituting for $d S$ and $d R$ and collecting terms yields

$$
d X=X\left(\mu-A_{t}+\frac{1}{2} \sigma^{2}+\frac{1}{2} B^{2}-\rho \sigma B\right) d t+X(\sigma-B) d W
$$

Since $Z$ and $H$ are both Wiener processes (Gaussian distributed), $W$ is also a Wiener process with variance $v^{2}=\sigma^{2}+B^{2}-2 \rho \sigma B$. Hence $d X=X \eta d t+X v d W$, where $\eta=\mu-A_{t}+\frac{1}{2} v^{2}$ and $v^{2}=\sigma^{2}+B^{2}-2 \rho \sigma B$

Lemma 3: The normalization factor $F(t, T)$ is

$$
F(t, T)=\exp \left(\mu \tau-A(t, T)+\frac{1}{2} v^{2} \tau\right)
$$

where $v^{2}=\sigma^{2}+B^{2}(t, T)-2 \rho \sigma B(t, T)$.

Proof: By Lemma $2 d X=X\left\{\mu-A_{t}+\frac{1}{2} v^{2}\right\} d t+X v d W$. Since the boundary condition is $X(t, t)=1$, then $X=1+\int_{0}^{\tau} X\left(\mu-A_{t}+\frac{1}{2} v^{2}\right) d u+\int_{0}^{\tau} X v d W$. Take expectation $\mathrm{E}(X)=1+\int_{0}^{\tau} \mathrm{E}(X)\left(\mu-A_{t}+\frac{1}{2} v^{2}\right) d u$. Hence $F(t, T)=\mathrm{E}(X)=\exp \left(\mu \tau-A+\frac{1}{2} v^{2} \tau\right)$.

Lemma 4: The discount factor, $\Upsilon(t, T)$, of a sample random path is as follows: 


$$
\Upsilon(t, T)=\frac{1}{R(t, T)}=\exp (-A(t, T)-B(t, T) H(\tau))
$$

with the boundary condition $\Upsilon(t, t)=1$.

Proof: Differentiating $\Upsilon(t, T)=\frac{1}{R(t, T)}$ using Ito's lemma and substituting for $d R=R\left(A_{t}+\frac{1}{2} B^{2}\right) d t+R B d H$, gives $d \Upsilon=-\Upsilon\left(A_{t}-\frac{1}{2} B^{2}\right) d t-\Upsilon B d H$.

Hence $\Upsilon(t, T)=\exp (-A-B H(\tau))$.

Lemma 5: The expected discount factor $\Lambda(t, T)$ is

$$
\Lambda(t, T)=\exp \left(-A(t, T)+\frac{1}{2} B^{2}(t, T) \tau\right)
$$

Proof: By Lemma $4 d \Upsilon$ follows a differential form of the geometric Brownian motion

$$
\begin{aligned}
& d \Upsilon=-\Upsilon\left(A_{t}-\frac{1}{2} B^{2}\right) d t-\Upsilon B d H . \text { The initial value is } \Upsilon(t, t)=1 . \text { Thus } \\
& \Upsilon=1-\int_{0}^{\tau} \Upsilon\left(A_{t}-\frac{1}{2} B^{2}\right) d u-\int_{0}^{\tau} \Upsilon B d H \text {. Taking expectation gives } \\
& \mathrm{E}(\Upsilon)=1-\int_{0}^{\tau} \mathrm{E}(\Upsilon)\left(A_{t}-\frac{1}{2} B^{2}\right) d u . \text { Hence } \mathrm{E}(\Upsilon)=\exp \left(-A+\frac{1}{2} B^{2} \tau\right) .
\end{aligned}
$$

\section{Proof of Theorem 1:}

Applying Lemma 4 to the option price model in Equation (5) gives

$$
C(t, T)=\mathrm{E}\left[S(t) \frac{X(t, T)}{F(t, T)}-K \frac{1}{R(t, T)}\right]^{+} .
$$


For simplicity, set $t=0$ and omit the time descriptors. Then,

$$
C=\int_{\frac{K}{S(0)} F}^{\infty} \operatorname{Pr}(S) \frac{1}{R}\left(\frac{S}{F}-K\right) d S=\underbrace{S(0) \int_{\frac{K}{S(0)} F}^{\infty} \operatorname{Pr}(S)\left(\frac{X}{F}\right) d S}_{I}-\underbrace{K \int_{\frac{K}{S(0)} F}^{\infty} \frac{1}{R} \operatorname{Pr}(S) d S}_{I I},
$$

where $\operatorname{Pr}(\cdot)$ stands for the probability density function.

Applying Lemma 2 for the random process $X$ yields $X(0, t)=e^{\mu t-A+\nu W} \cdot{ }^{38}$

We begin with the first part of Equation (14): $I=S(0) \int_{\frac{K}{S(0)} F}^{\infty} \operatorname{Pr}(S)\left(\frac{X}{F}\right) d S$.

Substituting for $F(0, t)=e^{\mu t-A+\frac{1}{2} v^{2} t}, X(0, t)=e^{\mu t-A+v W}$, and changing the variables for

$$
S(t)=e^{\mu t+\sigma W} \text { yields } I=S(0) \int_{\frac{\ln \frac{K}{S(0)}-A+\frac{1}{2} v^{2} t}{\sigma}}^{\infty} \operatorname{Pr}\left(e^{\mu t+\sigma W}\right) e^{-\frac{1}{2} v^{2} t+v W} e^{\mu t+\sigma W} \sigma d W
$$

Substituting for the log-normal probability density function, $\operatorname{LN}\left(0, \sigma^{2} t\right)$, of $S(t)$ :

$$
I=S(0) \int_{\frac{\ln \frac{K}{S(0)}-A+\frac{1}{2} v^{2} t}{\sigma}}^{\infty} \frac{1}{\sqrt{t} \sqrt{2 \pi}} e^{-\frac{1}{2}\left(\frac{W}{\sqrt{t}}-v \sqrt{t}\right)^{2}} d W
$$

Changing the variables, $W=\hat{W} \sqrt{t}$, such that $\hat{W} \sim \mathrm{N}(0,1)$, and using the symmetry

property gives $\quad I=S(0) \mathrm{N}\left(\frac{\ln \frac{S(0)}{K}+A-\frac{1}{2} v^{2} t}{\sigma \sqrt{t}}+v \sqrt{t}\right)$.

\footnotetext{
${ }^{38}$ Notice that the process $S(T)$ is a special case of the process $X(t, T)$ when $A(t, T)=0$ and $B(t, T)=0$. The process $\Upsilon(t, T)$ is also a special case of the process $X(t, T)$ when $\mu=0$ and $\sigma=0$.
} 
We apply the same procedure to part II of Equation (14), and obtain the call formula $C=S(0) \mathrm{N}\left(\frac{\ln \frac{S(0)}{K}+A-\frac{1}{2} v^{2} t}{\sigma \sqrt{t}}+v \sqrt{t}\right)-K e^{-A+\frac{1}{2} B^{2} t} \mathrm{~N}\left(\frac{\ln \frac{S(0)}{K}+A-\frac{1}{2} v^{2} t}{\sigma \sqrt{t}}-B \sqrt{t}\right)$

Proof of Theorem 3: The put-call parity can be written as

$K \Lambda(t, T)=P(t, T)+S(t)-C(t, T)$, where $\Lambda(t, T)=\mathrm{E}[\Upsilon(t, T)]$

Set $m=\frac{\ln \frac{S(0)}{K}+A-\frac{1}{2} v^{2} \tau}{\sigma \sqrt{\tau}}+v \sqrt{\tau}$ and $n=\frac{\ln \frac{S(0)}{K}+A-\frac{1}{2} v^{2} \tau}{\sigma \sqrt{\tau}}-B \sqrt{\tau}$.

Substituting for the prices of call and put options gives

$$
P(t, T)+S(t)-C(t, T)=K e^{-A+\frac{1}{2} B^{2} \tau}
$$

Using Lemma 5: $\quad K \Lambda(t, T)=P(t, T)+S(t)-C(t, T)$. 